07;09

\title{
Повышение выхода люминесценции диоксида циркония
}

\author{
(C) С.В. Никифроров, В.С. Кортов, А.Н. Киряков, С.Ф. Конев, \\ А.А. Меньшенина
}

Уральский федеральный университет им. Б.Н. Ельцина, Екатеринбург E-mail: s.v.nikiforov@urfu.ru

Поступило в Редакцию 11 июля 2017 г.

Исследовано влияние высокотемпературной обработки в вакууме в присутствии углерода в качестве восстановителя на люминесцентные свойства диоксида циркония. Показано, что рост интенсивности импульсной катодолюминесценции при $480 \mathrm{~nm}$ и термолюминесценции в доминирующем пике при $500 \mathrm{~K}$ при такой обработке обусловлен термохимическим окрашиванием исходных образцов с образованием кислородных вакансий, обнаруживаемых методом электронного парамагнитного резонанса. Описанная методика повышения выхода люминесценции $\mathrm{ZrO}_{2}$ может применяться при его использовании в оптоэлектронике, фотонике и радиационной дозиметрии.

DOI: 10.21883/PJTF.2017.23.45276.16962

Люминесцентные свойства диоксида циркония $\left(\mathrm{ZrO}_{2}\right)$ интенсивно изучаются, поскольку данный материал является перспективным с точки зрения его использования в современной оптоэлектронике, фотонике, а также люминесцентной дозиметрии ионизирующих излучений [1]. Основной технический параметр люминофора — выход люминесценции, поэтому актуальной проблемой является разработка способов его повышения. Эта задача особенно важна для радиационностойких наноструктурных люминофоров, характеризующихся, как правило, более низким выходом люминесценции, чем их объемные аналоги.

Известно, что люминесцентные свойства широкозонных оксидов во многом определяются присутствием кислородных вакансий в разных зарядовых состояниях, формирующих центры свечения $F$-типа [2]. Изменяя концентрацию этих дефектов, можно управлять выходом люминесценции данного класса материалов. Для создания кислородных вакансий в оксидах металлов используется их термохимическое окраши- 
вание в восстановительной среде, в частности, в присутствии углерода. Данный способ ранее успешно применялся для синтеза ультрадисперсных люминесцирующих керамик на основе оксидов алюминия и магния [3,4]. Известны работы, в которых исследовалось влияние на люминесцентные свойства $\mathrm{ZrO}_{2}$ термохимического окрашивания при низком парциальном давлении кислорода [5], а также в среде $\mathrm{H}_{2} / \mathrm{Ar}$ [1]. Однако влияние термохимического окрашивания в присутствии углерода на выход люминесценции диоксида циркония изучено недостаточно.

Целью настоящей работы является изучение влияния термообработки в восстановительных условиях, обеспечиваемых присутствием углерода, на люминесцентные свойства диоксида циркония.

В качестве исходного материала использовался нанопорошок моноклинного диоксида циркония, полученный плазмохимическим методом (компания „Плазмотерм“, Россия) с размером частиц 70-105 nm. Для изготовления образцов нанопорошки подвергались холодному одноосному прессованию с давлением $1000 \mathrm{kgf} / \mathrm{cm}^{2}$. Полученные прессовки имели диаметр $5 \mathrm{~mm}$ и толщину $1 \mathrm{~mm}$. Термообработка образцов (субтрактивное окрашивание) проводилась в электровакуумной печи СНВЭ-9/18 $\left(10^{-3}-10^{-4}\right.$ Torr $)$ при температуре $1400^{\circ} \mathrm{C}$ в присутствии углерода (в графитовых тиглях) и без него при времени изотермической выдержки от 30 до $180 \mathrm{~min}$. Образцы, термообработанные в присутствии углерода, окрашивались в черный цвет, вероятно из-за образования карбида циркония, и обладали очень низким выходом люминесценции. Для устранения почернения образцы после термообработки в электровакуумной печи отжигались в муфельной печи на воздухе при температуре $900^{\circ} \mathrm{C}$ в течение часа. Известно, что при 700-900 ${ }^{\circ} \mathrm{C}$ происходит разложение карбида циркония за счет взаимодействия с кислородом с образованием $\mathrm{ZrO}_{2}$ и углерода [6]. Нами было установлено, что в отожженных по указанной методике образцах почернение исчезало, а их поверхность приобретала белый цвет.

Рентгенодифракционные исследования образцов проводились с помощью дифрактометра XPert PRO MPD PANalitical в Cu-излучении с бета-фильтром на вторичном луче при комнатной температуре. Напряжение трубки составляло $4 \mathrm{kV}$, ток анода $30 \mathrm{~mA}$. Спектры электронного парамагнитного резонанса (ЭПР) измерялись на приборе фирмы Bruker ELEXSYS 580 с резонансной частотой $9.27 \mathrm{GHz}$ (волновое число $0.31 \mathrm{~cm}^{-1}$ ) в интервале изменения индукции магнитного поля от 480 до $6000 \mathrm{G}$.

Письма в ЖТФ, 2017, том 43, вып. 23 
Для измерения импульсной катодолюминесценции (ИКЛ) применялся спектрометр „КЛАВИ“, оснащенный ускорителем электронов с энергией $130 \mathrm{keV}$ (длительность импульса $2 \mathrm{~ns}$, плотность тока $60 \mathrm{~A} / \mathrm{cm}^{2}$ ). Этот же электронный пучок использовался для возбуждения термолюминесценции (ТЛ). Поглощенная доза от одного импульса составляла величину $1.5 \mathrm{kGy}$. ТЛ измерялась при линейном нагреве со скоростью $2 \mathrm{~K} / \mathrm{s}$ с помощью ФЭУ-130 с максимумом спектральной чувствительности $400-420 \mathrm{~nm}$.

Известно, что при $1175^{\circ} \mathrm{C}$ наблюдается фазовый переход оксида циркония из моноклинной фазы в тетрагональную [7]. Фазовый состав термообработанных образцов исследовался методом рентгеновской дифракции. Результаты показали, что образцы, термообработанные без углерода, состояли на $100 \%$ из моноклинной фазы, как и исходные. В образцах, отожженных с углеродом, наблюдалось уменьшение содержания моноклинной фазы до $74 \%$ и образование тетрагональной фазы. Возможной причиной такого эффекта является возникновение кислородных вакансий с высокой концентрацией в термообработанных с углеродом образцах, которые могут стабилизировать тетрагональную фазу в $\mathrm{ZrO}_{2}$ [8]. Такая ситуация имеет место при стабилизации тетрагональной фазы оксидом иттрия, где кислородные вакансии образуются из-за необходимости обеспечения компенсации заряда [8].

Присутствие кислородных вакансий в термообработанных образцах подтверждается методом ЭПР. На рис. 1 приведены ЭПР-спектры для исходных образцов и термообработанных в присутствии углерода и без него. Видно, что все ЭПР-спектры характеризуются сигналом с $g$-фактором 1.96, обусловленным парамагнитными дефектами, представляющими собой $4 d^{1}$-ионы $\mathrm{Zr}^{3+}$ [9]. Кроме того, в спектрах образцов, отожженных без углерода и с углеродом, появляется сигнал ЭПР с $g$-фактором 2.005. Его величина очень близка к $g$-фактору, свойственному $F^{+}$-центру в $\mathrm{ZrO}_{2}$ (2.003) [9]. Таким образом, полученные результаты подтверждают наличие повышенной концентрации кислородных вакансий в термообработанных образцах по сравнению с исходными, что позволяет ожидать изменения их люминесцентных свойств. В настоящей работе выход люминесценции образцов $\mathrm{ZrO}_{2}$ оценивался по интенсивности свечения ИКЛ и пиков ТЛ.

На рис. 2 приведены спектры ИКЛ исследуемых образцов. Видно, что у всех образцов наблюдается известная из литературы полоса ИКЛ при $480 \mathrm{~nm}$ [10]. Результаты наших исследований показывают, что 


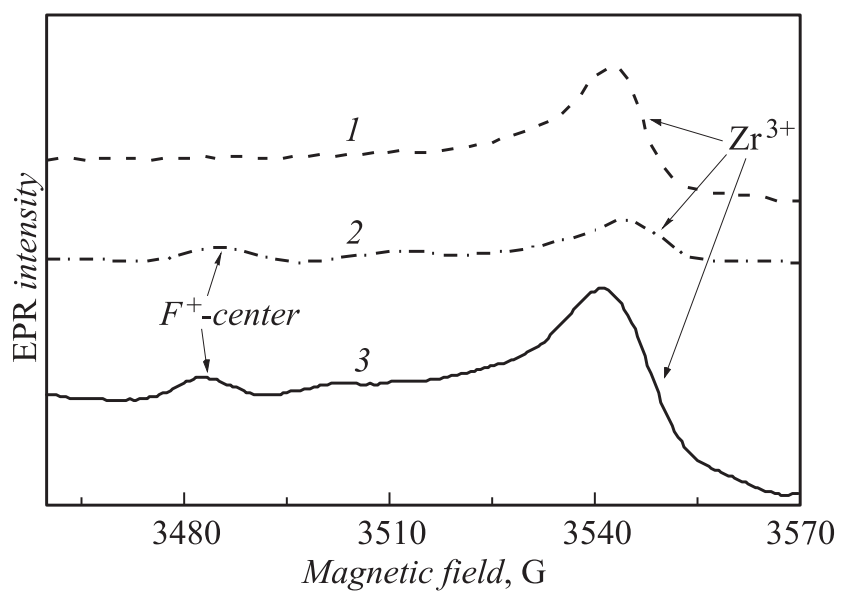

Рис. 1. ЭПР-спектры образцов $\mathrm{ZrO}_{2}$ : исходных (1), отожженных без углерода (2) и в присутствии углерода (3).

высокотемпературная обработка приводит к увеличению в 2-3 раза интенсивности ИКЛ в данной полосе по сравнению с исходными образцами (кривая 2). При этом термообработка в присутствии углерода вызывает более существенное увеличение (в 6-7 раз) интенсивности ИКЛ (кривая 3).

Относительно природы полосы люминесценции при $480 \mathrm{~nm}$ в диоксиде циркония нет единого мнения. В работе [5] интенсивность фотолюминесценции в данной полосе возрастала при уменьшении парциального давления кислорода при выращивании пленок $\mathrm{ZrO}_{2}$. На основе сопоставления этих данных и результатов квантово-химических расчетов был сделан вывод о связи указанной полосы с кислородными вакансиями. Эта точка зрения поддерживается и другими авторами, по мнению которых полоса при $480 \mathrm{~nm}$ обусловлена релаксацией $F^{+}$-центра [11]. Однако имеются литературные данные об отсутствии роста фотолюминесценции в этой полосе в результате термообработки наноструктурного моноклинного $\mathrm{ZrO}_{2}$ в атмосфере $\mathrm{H}_{2} / \mathrm{Ar}$ [1]. Авторы данной работы поддерживают высказанное ранее [10] предположение о связи полосы люминесценции при $480 \mathrm{~nm}$ с ионами титана $\left(\mathrm{Ti}^{3+}\right)$. Наши результаты исследования ИКЛ могут свидетельствовать в пользу

Письма в ЖТФ, 2017, том 43, вып. 23 


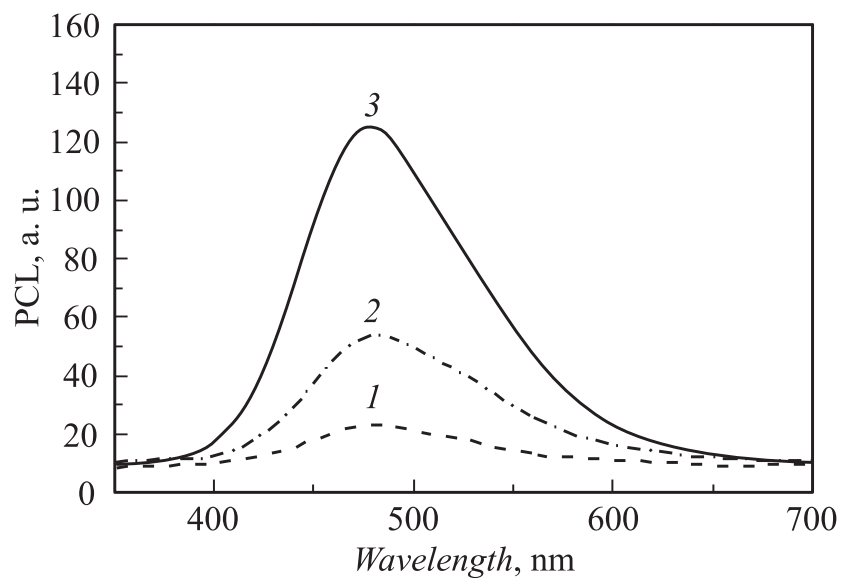

Рис. 2. Спектры ИКЛ образцов $\mathrm{ZrO}_{2}$ : исходных (1), термообработанных в течение $180 \mathrm{~min}$ без углерода (2), в присутствии углерода (3).

участия кислородных вакансий, создаваемых при термохимическом окрашивании, в формировании полосы люминесценции при $480 \mathrm{~nm}$ в $\mathrm{ZrO}_{2}$. При этом термообработка в присутствии углерода приводит к более высокой концентрации кислородных вакансий, чем обработка без него, что вызывает дополнительный рост интенсивности ИКЛ при $480 \mathrm{~nm}$ (рис. 2).

Нами также было исследовано влияние термохимического окрашивания на ТЛ диоксида циркония, облученного импульсным электронным пучком с дозой $15 \mathrm{kGy}$ (рис. 3). Видно, что в результате термообработки без углерода интенсивность ТЛ увеличилась на порядок. При этом на кривой ТЛ наблюдаются пики: $A$ при $340 \mathrm{~K}, B$ при $400 \mathrm{~K}$ и $C$ при $500 \mathrm{~K}$. Доминирующим является пик ТЛ при $500 \mathrm{~K}$. Высокотемпературная обработка $\mathrm{ZrO}_{2}$ в присутствии углерода вызывает намного более существенный рост ТЛ пика $C$ и небольшое его смещение в область пониженных температур. Известно, что в спектре ТЛ данного пика доминирует полоса $480 \mathrm{~nm}$ [12], рост которой в спектрах ИКЛ в результате термообработки был установлен ранее (рис. 2). Кроме того, имеется точка зрения о связи ловушек, обусловливающих пик $C$ при $500 \mathrm{~K}$, с кислородными вакансиями [1]. Таким образом, наблюдаемый рост ТЛ пика при $500 \mathrm{~K}$ при термообработке можно объяснить созданием в этих

Письма в ЖТФ, 2017, том 43, вып. 23 


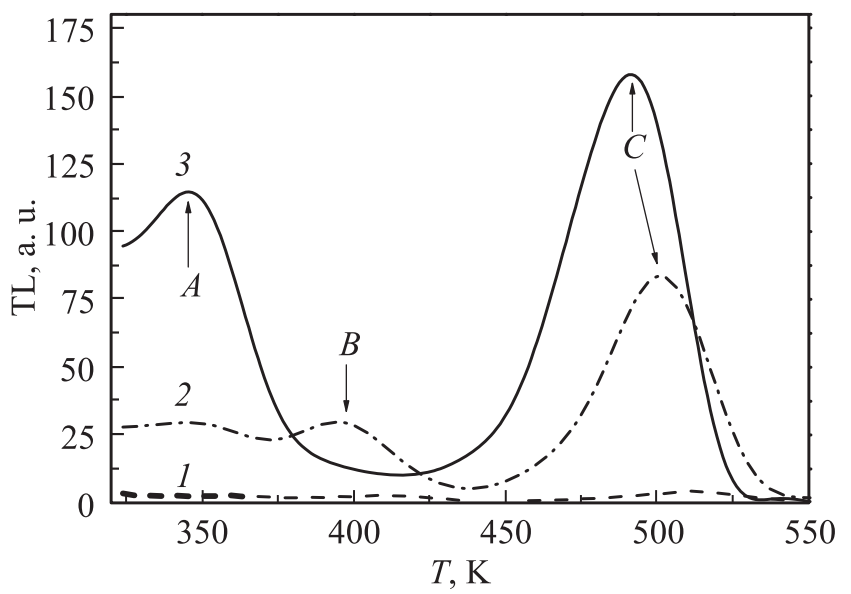

Рис. 3. ТЛ диоксида циркония: исходных образцов (1), термообработанных в течение $30 \mathrm{~min}$ без углерода (2), в присутствии углерода (3).

условиях центров свечения и захвата, обусловленных кислородными вакансиями. Аналогичная закономерность роста интенсивности ТЛ наблюдается также и для пика $A$ при $340 \mathrm{~K}$, связанного с мелкими ловушками, ответственными за послесвечение диоксида циркония при комнатной температуре $[10,12]$. Для пика $B$ наблюдается более сложное поведение интенсивности ТЛ, в частности ее снижение для образцов, обработанных с углеродом, по сравнению с интенсивностью ТЛ для образцов, окрашенных без его присутствия. Данный эффект требует дополнительных исследований.

Таким образом, в работе показана эффективность методики повышения выхода люминесценции диоксида циркония при термохимическом окрашивании образцов в вакууме в присутствии углерода. Повышение выхода люминесценции связано с образованием высокой концентрации кислородных вакансий, наличие которых в термообработанных образцах подтверждено методом ЭПР. Установлено, что окрашивание образцов в присутствии углерода приводит к более существенному увеличению интенсивности ИКЛ при $480 \mathrm{~nm}$ и ТЛ доминирующего пика при $500 \mathrm{~K}$, чем при термообработке без углерода, что является важным результатом для практического применения диоксида циркония в качестве люминофора. 


\section{Список литературы}

[1] Kiisk V., Puust L., Utt K., Maaros A., Mandar H., Viviani E., Piccinelli F., Saar R., Joost U., Sildos I. // J. Lumin. 2016. V. 174. P. 49-55.

[2] Popov A.I., Kotomin E.A., Maier J. // Nucl. Instrum. Methods Phys. Res. B. 2010. V. 268. P. 3084-3089.

[3] Kortov V.S., Zvonarev S.V., Kiryakov A.N., Ananchenko D.V. // Rad. Meas. 2016. V. 90. P. $196-200$.

[4] Nikiforov S.V., Kortov V.S., Petrov M.O. // Rad. Meas. 2016. V. 90. P. 252-256.

[5] Perevalov T.V., Gulyaev D.V., Aliev V.S., Zhuravlev K.S., Gritsenko V.A., Yelisseyev A.P. // J. Appl. Phys. 2014. V. 116. P. 244109.

[6] Крутский Ю.Л., Дюкова К.Д., Баннов А.Г., Максимовский Е.А., Ухина А.В., Крутская Т.М., Нецкина О.В., Кузнецова В.В. // Научн. вестн. НГТУ. 2015. T. 60. № 3. C. 92-205.

[7] Cong Y., Li B., Yue S., Fan D., Wang X. // J. Phys. Chem. C. 2009. V. 113. P. 13974-13978.

[8] Smits K., Sarakovskis A., Grigorjeva L., Millers D., Grabis J. // J. Appl. Phys. 2014. V. 115. P. 213520.

[9] Frolova E.V., Ivanovskaya M.I. // Mater. Sci. Eng. C. 2006. V. 26. P. 1106-1110.

[10] Wang Z., Zhang J., Zheng G., Liu Y., Zhao Y. // J. Lumin. 2012. V. 132. P. 2817-2821.

[11] Aleksanyan E., Kirm M., Feldbach E., Harutyunyan V. // Rad. Meas. 2016. V. 90. P. 84-89.

[12] Nikiforov S.V., Kortov V.S., Savushkin D.L., Vokhmintsev A.S., Weinstein I.A. // Rad. Meas. 2017. http://dx.doi.org/10.1016/j.radmeas.2017.03.020 